\title{
The Significance of the Multicultural Education Based on the Experiential Learning of a Local Community
}

\author{
PhD. Heejin Yun \\ BK21Plus Glocal Multicultural Education Professional Development Institute, Korea \\ PhD Cand. Juanjuan Zhang \\ Department of Multicultural Education, Inha University, Korea
}

\begin{abstract}
The multicultural education was originally discussed in the Europe and the North America. It was introduced to South Korea more than 20 years ago and it has been discussed earnestly in South Korea. It began with the increase of Southeastern Asian immigrant workers and marriage-based immigrants in the late 1990s. People began to discuss the multicultural education as the awareness and demand regarding the human rights of immigrants, Korean language education, and the children of immigrants increased. Afterward, the multicultural education has become an education for the majority since the concept was extended to the society, although it once was conducted within the category of immigrants. The multicultural education, which has been taking place in South Korea, mostly consists of one-time experiential learning such as adding a multicultural element in a regular coursework, introducing other countries, or giving a chance to experience languages, foods, or clothes of other countries. The multicultural education utilizing the experiential learning is characterized by creative experiential activities, its association with the overall curriculum, and the connection with local communities. This study identified the significance of the multicultural education based on the experiential learning by examining the elements of the multicultural education.
\end{abstract}

Keywords: Multiultural education, experiential learning, space storytelling, multi-cultural space,

\section{INTRODUCTION}

As creativity is emphasized as a driving force for future society, the educational field is also changing accordingly. In the 'teaching education', in which the teacher communicates specific subject knowledge to the students, it is being developed as 'self-discovery education' in which students themselves seek information and problem solving methods. These changes led to the universalization of integrated education that encompasses curricular educational knowledge, critical thinking, and problem - solving abilities, without limiting it to the scope of curriculum such as language, mathematics, and science. As a result, the school of learning, a school that spent all day sitting in line with a blackboard in a square room, is also expanding and moving dynamically. Extended learning centers are moving away from the school premises to the community. Especially, this experience is getting stronger with emphasis on experiential learning such as 'field experience day', 'selfstudy day', 'creative discretion day', 'day without backpack'.

In recent years, with the emphasis on multicultural education in Korea, experiential learning for this purpose is gradually increasing. In the late 1990s, as the number of migrant workers and marriage immigrants from Southeast Asia increased in Korean society, the human rights of immigrants, Korean education, and awareness and demand of immigrant children increased. As a result, the education for adaptation to Korean life is mainly performed within the category of immigrants. Since 2010, the necessity of multicultural education has expanded to the society as a whole, and multicultural education has been carried out at the level of social subjects and each subject in each school.

In this paper, we review the present situation of multicultural education based on experiential learning, which is a small scale in I high school in I city, and discuss its improvement plan. In particular, we discuss the introduction of storytelling skills to realize the education that combines knowledge, experience, and feelings of students, the essence of experiential learning. 


\section{MULTICULTURAL EDUCATION AND EXPERIENTIAL LEARNING}

Multicultural education through experiential learning, which is one of the leaner = centered curriculum, is emphasized by many educators in that students directly see and interact with diverse cultures. In this paper, we propose a methodology for learning-based learning in Korea. Multicultural education, which has to recognize, understand and sympathize with the new phenomenon of cultural diversity, can make educational effect more easily through such experiential learning.

In many cases, experiential learning, which means education that allows a learner to manipulate objects directly or experience them to use them easily in real life and create new knowledge, is often performed outside the classroom. This experiential learning has been misunderstood to mean the physical activity outside the school. Dewey believed that experience was possible through specific activities, experiences after reflection, and reflective thinking. In other words, it can be said that true experience is achieved only when new changes are made in the learner through these concrete experiences (Kim and Lee, 2001). In this sense, experiential learning is not about accepting what the teacher has injected, whether it is to acquire any skill or to verify the theory, but it is necessary for the learner to make intelligent. It can be regarded as an activity involving emotional activities (Lee, 2013).

Nevertheless, a large number of experiential learning is carried out in the classrooms by experiential learning in the community. In addition, under the name of experiential learning, education is being held to visit museums, exhibition halls, concerts, and so on. Yang (2001) pointed out the limits of experiential learning in Korea. First, the theoretical background and reason for experiential learning were not clearly established. Second, they do not provide specific materials and guidance for conducting experiential learning, so they depend on the teacher's experience. Third, many teachers who are familiar with traditional teaching methods are not familiar with the new teaching method of experiential learning. Although many teachers perceive the educational meaning and necessity of experiential learning, the process of actually implementing it is not organized and educated, so the expectation of the teacher's experience is staying in the learning method.

This trend is stronger in multicultural education, which has not been in its long history. In Korea, full-fledged multicultural education was launched through the 2007 revision curriculum. In the general revision of the 2007 revised curriculum, the concept of a single nation, a bloodline, the Korean people, the pure blood religion tradition, and a single nation were deleted. In the 2009 revised curriculum, contents of multicultural education through curriculum time as well as curriculum contents were accepted. In particular, the 2009 revised curriculum includes the provision of special classes for multicultural students, curriculum management in consideration of Korean language ability, and support for learning (Jeon and Kim, 2013). In addition, in the current curriculum of Korea, 2015 revised curriculum, the multicultural education is selected as a subject of cross-curricular learning along with democracy education and human rights education among elementary and secondary school curriculum. (National Curriculum Information Center, 2017.04.18, search).

Multicultural education is an education aimed at social integration by improving the curriculum and education system so that all students with various social classes, races, ethnicities, gender, backgrounds can experience equal educational opportunities (Banks, 2002/2008). The rise of multicultural education in Korea is due to the rapid increase of migrant workers, foreign students, and married immigrant women, which have increased since the late 1990s. The number of foreigners residing in Korea, which was 65,673 in 1992, increased by 4.4 times to 287,923 in 2002 and increased to 932,983 in 2012 and 1,143,087 in 2015 (Korean Statistical Information Service; 2017.04.18.search).

Most of the foreign nationals who are staying in Korea are from Asia, and especially the Chinese and Korean foreigners account for $50 \%$ of all foreigners, meaning 'race' does not have much meaning in Korea's multicultural education. This is not only because foreigners in Korea are not so different from the outside, but also because of the large percentage of Chinese Koreans who moved to China in the early 1920s and early 20s. However, as mentioned above, Koreans received 'public education' of 'bloodline' and 'Korean people' until the revision of the 2007 revision curriculum, so the disparity in the diversity of the 'people' is as big an issue as racial controversy overseas. In addition, migrant workers and married immigrant women are often referred to as the driving forces of multicultural society. Migrant workers make it difficult for Korean young people to work in the Korean manufacturing industry, so the youth unemployment rate has risen, or the marriage immigrant women are treated as people who choose marriage for economic reasons in poor countries.

This situation seems to be due to the increase in the number of foreigners in Korean society by about 18 times over 15 years and the economic argument over the background of the increase of humanity. Kim and Kim (2008) pointed out that 
'multicultural education' can be defined as' the correct understanding of the culture in which the citizens belong in their own self-establishment, the way of life and social relations in multicultural society, Values and attitudes' to emphasize the need for education in various cultures. The multicultural education, which has been taking place in South Korea, mostly consists of one-time experiential learning such as adding a multicultural element in a regular coursework, introducing other countries, or giving a chance to experience languages, foods, or clothes of other countries. Multicultural education in relation to curriculum is carried out through related units in each subject, and creative experiential activities consist of single - time education in comparison and time. Multicultural education through creative experiential activities can be a one-time eventoriented education, but it has the advantage of having various experiences (Jeon, 2015).

In order for multicultural education to be meaningful to students, it is necessary not to accept other cultures as information, but to organize knowledge by meeting with people of various cultures. Through experiential learning, the learner constructs knowledge through a process of thinking about knowledge in a practical context and meaningfully interpreting his experience. Multicultural education is more effective if it is centered on the process rather than the result. Students can recognize and understand cultural diversity scattered around us through specific cultural experiences. It is time to design multicultural education that is suitable for Korean multicultural situation, especially the design of multicultural education that utilizes experiential learning.

\section{SIGNIFICANCE OF MULTICULTURAL EDUCATION EXPERIENCE LEARNING UTILIZING MULTI-CULTURAL SPACE}

The multicultural education utilizing the experiential learning is characterized by creative experiential activities, its association with the overall curriculum, and the connection with local communities. Each place in a local community forms the memories, emotions, and thoughts of people and, consequently, it is important to form the value of a person. The internal space is soon exteriorized and the external space becomes the interior. The place and the space of the interior and exterior resemble each other. In other words, our perceptions and experiences are expressed in space and the memories and emotions of the space are integrated into our interior. Park (2012) named Multicultural Space where it can grasp the traces of life of various people. He explained that humans exist as a result of the connection between human beings and the environment surrounding them, and through the expression of this life, humans exist. Multicultural space is a place where people can grasp the traces of life in various spaces and various people making a relationship.

Choi (2009) defined multicultural space as a space where various cultures collide and produce multicultural phenomena. He explains that multicultural space has the following characteristics. First, multicultural space carries socio - spatial phenomena related to cultural exchange and coexistence that are accelerating in the global - local level. Multicultural space is a theater for cultural exchanges formed by the historical movement of people and culture, and a stage for performing hybrid identity (Keith, 2005). Second, the multicultural space is concerned with policies and plans for cultural exchange and mixing that are spreading globally and locally. Third, multicultural spaces embody normative ethics and democratic ideals that presuppose recognition of cultural diversity. The multicultural space is a recognition space that recognizes the cultural diversity of its members. It promotes the development of democracy on the premise of mutual recognition of its members.

The research on multicultural spaces is mainly carried out in the fields of politics, sociology, anthropology, geography, architecture, etc., in the field of multicultural space, policy plans, formation of multicultural spaces and research on social organization (Kong, 2013). In many cases, the multicultural space is limited to a range of foreigner / immigrant populations, historical sites of migration, and so on. Kim (2009) sees foreign residents of a specific country living in a specific area in a Korean society as a multicultural space with religious facilities and stores scattered around them. He cited the KoreanChinese village, Chinatown as a dense area of Korean-Chinese, Seorae village as a dense area of French people, and Russian and Central Asian village as a major commercial area of Uzbek and Russians.

In other words, multicultural space means a space where prisoners can secure cultural diversity through spatial experience. Multicultural space is a space where everyone in our society lives. However, in a narrow range, multicultural spaces can be classified as multicultural spaces, where foreigner / immigrant populations, and places where foreigners have exchanged in history, are considered to be different from those of my life.

The experiential learning using this multicultural space has the following significance. Firstly, it can expand learners' multicultural knowledge through the context and context of multicultural space. Multicultural education in each subject or cross-sectional level that is constructed within the school classroom is composed of type. By experiencing the multicultural space, learners who are in a multicultural situation will use the information on multicultural education that preceded the 
school. It also enables a deeper understanding by experiencing the history and situation in which multicultural spaces are formed and maintained.

Secondly, by experiencing the multicultural space connected with the local community, the daily life of cultural diversity can be realized. Event-based multicultural education, which consists of clothing and food experiences in a particular country, can give learners a prejudice that 'multiculturalism' exists in special circumstances. However, cultural diversity always exists together in situations where learners are not aware of them. Experiential learning in a multicultural space where foreigners I migrants actually reside and conduct commercial activities informs learners that this form of life is ordinary and not ordinary, and the learner can also experience it.

Thirdly, it enables reflection and critical thinking about multicultural society. In order for experience to have real meaning in experiential learning, learners must organize their own learning through interpreting experiences and giving meaning to them in relation to the world. Exploring multicultural spaces and examining the life patterns of people living there will allow learners to look at themselves and have a critical view of society.

\section{CONCLUSION}

The goal of multicultural education cannot be achieved by simply teaching knowledge about multiculturalism. This study suggests experiential learning that utilizes multicultural space in order to develop learners' creativity and achieve the purpose of multicultural education which is related to real life. Experiential learning using multicultural space can expand learners' multicultural knowledge through the context and context of multicultural space, the cultural diversity can realize the usualness through the multicultural space connected with the community, it is meaningful that it enables reflection and critical thinking about multicultural society.

In order for the experiential learning that utilizes this multicultural space to operate more effectively, it should pay attention to the story of the multicultural space. Multicultural space is a pathway for transnational action and a channel for such performance. Multicultural education that uses multicultural space needs storytelling to connect the story of the space with me because there is a danger that it can only stay in the life of others, the story of others. The learner experiences the story of space and appropriates it, so that the multicultural space changes from the space of others to the space of my own. In order to enable such space storytelling, the instructor who guides the experiential learning should create a way to intertwine the interests and interests of the learners, the story of the space, and the knowledge to convey. And do not make boundaries on these paths.

However, it is not easy to carry out multicultural education using multicultural space without the support of schools and government. In case of experiential learning, it is necessary to solve problems such as cost problem and preparation for safety accident. And it is not a simple visit to the space, but it should organically take precedence learning and follow-up learning to reflect the individual's reflection.

The multicultural education should provide diverse experiences to learners by using the multicultural characteristics of a local community by closely connecting with the local community. Moreover, in a long-term, it should encourage the members of the society to participate in the multicultural education. It is expected that the results of this study convert the current simple visiting learning (e.g., immigration community visit, foreign culture contact historical heritage, and museum visit), which is conducted under the name of the multicultural education, into more concrete, systematic, and practical learning with having multicultural educational elements.

\section{REFERENCES}

[1] Banks, J. A. (2008). Introduction of Multicultural Education. (Mo, K. Y. et al. Trans.). Academy Press. (Original work published 2002).

[2] Keith, M. (2005). After the Cosmopolitan? Multicultural Cities and the Future of Racism. Routledge.

[3] Choi, B. D. (2009). "Multi-Cultural Space and Glocal Ethics: From Cultural Space ofTransnational Capitalism to Space of Recognition Struggle". Journal of The Korean Association of Regional Geographers 15(5). 635-654.

[4] Kim, H. K., Lee, S. D. (2001). "A View on Experiential Learning of Practical Arts Education", Journal of Korean Practicial Arts Education 7(1), 83-104.

[5] Kim, I. R. (2009). "The Multi-cultural theory and Space in Korea: The case of Seoul". Journal of Korean PhotoGeographers 19(4). 95-106.

[6] Kim, S. M., Kim, Y. S. (2008). Understanding of Multicultural Education. Korean Culture Press. 
[7] Lee, J. Y. (2013). "The use of the field experience learning in a college liberal art course: A case study of the field experience learning of reconsidering the awarness of unification", The Review of Korean Studies 7(5), 495-521.

[8] Jeon, Y. Y. (2015). A Culture-Cognitive Theoretical Study on Culture and Arts Activities in Multicultural Education: Focusing on Corporality in Activities (Doctoral dissertation, Inha University).

[9] Jeon, Y. Y., Kim, Y. S. (2013). "A Study on Multicultural Experiences of Secondary Student participating the Arts and Culture Activities of 'the Borderless Village RPG Program'", Korean journal of culture and arts education studies 8(2), 55-77.

[10] Kong, Y. K. (2013). "The Dualistic Viewpoint and Discrimination towards Multi-Cultural Spaces". Journal of Korean Studies 48, 183-214.

[11] Park, S. K. (2012). "Investigations on Educational Significance of 'Multicultural Space' in Multicultural Education". Journal of cultural and historical geography 24(2), 111-122.

[12] Yang, M. K. (2001). "Exploring the meaning and conditions of Experiential Learning", The Journal of Eudcational Research 39(1), 167-196.

[13] National Curriculum Information Center. (2017.04.18 search). http://www.ncic.go.kr.

[14] Korean Statistical Information Service. (2017.04.18 search). http://kostat.go.kr 